CORRESPONDENCE

\title{
The impact of blood donation on bone marrow harvest efficiency
}

(c) The Author(s), under exclusive licence to Springer Nature Limited 2022

Bone Marrow Transplantation (2022) 57:507-509; https://doi.org/ 10.1038/s41409-022-01573-1

\section{TO THE EDITOR:}

Bone marrow (BM) donation is a procedure that takes place in an operating room. In many hospitals, autologous blood is collected from donor before the harvest and reinfused at the time of the donation, similar like in the case of other planned surgical operations. Blood donation causes reduced preoperative hemoglobin concentration, but autotransfusion after BM collection compensates this effect [1,2].

The intention of autotransfusion is to increase patient safety, but this procedure has its disadvantages. The donors are exposed to the risk of infections, allergic reactions, or misidentification of blood unit due to human errors. Sometimes operation is canceled or postponed, and autologous unit must be disposed of. Moreover, hospitals bear the costs of collection, storage and transfusion of red cell concentrates [3-5]. On the other hand, the blood loss stimulates hematopoiesis, so it is possible that preparing for autotransfusion has an impact on the quality of collected BM.

The aim of this study was to assess whether blood donation before harvest affects efficiency of BM collection, defined as the number of nucleated cells and CD34-positive cells in the product. Additionally, the effect of autotransfusion on hemoglobin level in donors before and after BM donation were evaluated.

In the Maria Sklodowska-Curie National Research Institute of Oncology, Gliwice Branch, Poland, about 35-45 BM donations from healthy donors are performed every year. Until March 2020, decision regarding autotransfusion depended on the expected volume of BM to be collected. The procedure was not carried out if the weight difference was greater than $30 \mathrm{~kg}$ in favor of the donor. Therefore, autologous blood collection used to be performed in most donors. Single blood unit was collected on the day of initial workup. It was further processed to obtain 1 unit of red blood cell concentrate and 1 unit of plasma.

In March 2020, due to SARS-Cov-2 pandemic, blood donation for autotransfusion in donors was abandoned. This situation gave an opportunity to check, if the donation of blood has an impact on the number of leukocytes and CD34 cells in collected BM.

BM was aspirated under general anaesthesia, from both pelvic bones. According to local procedures, the volume of BM and WBC was measured during donation. If total number of nucleated cells was sufficient for transplantation, the donation was completed. The collection was also finished if the volume of BM reached $20 \mathrm{ml}$ per kg of donor body weight. For donors with pre-collected autologous blood, red blood cell concentrate and plasma were transfused during or immediately after harvest. All individuals who donated autologous blood underwent autotransfusion. According to our institutional standard operating procedures, transfusion of allogeneic blood is performed when $\mathrm{Hb}$ level is lower than $8 \mathrm{~g} / \mathrm{l}$; allogeneic transfusion was not required for any donor in this study.

The blood samples were taken on the day of initial workup, one day before and one day after the harvest. Blood and BM samples were analyzed using Sysmex XN-2000 Hematology System. The percentage of CD34-positive cells in the product was evaluated according to ISHAGE guidelines, as described [6].

In our study, a total of 53 BM harvests performed from healthy, unrelated donors were analyzed. The donations smaller than 500 $\mathrm{ml}$ were excluded from the analysis, because the donors for pediatric patient had never been planned for autotransfusion. Total number of $20 \mathrm{BM}$ donations from healthy donors were carried out between March 2020 and March 2021. Those donors were not referred for autotransfusion. The control group consisted of 33 donors, who underwent harvest between January 2019 and March 2020. Only one difference between the cohorts was found: the donors not referred for autotransfusion were older than control group (medians: 37 years vs 25 years, $p<0.001$ ). Other factors like gender, weigh of donors, and interval between work up and BM donation were comparable. Both cohorts had comparable hemoglobin levels on the day of initial workup, on the day before and one day after the donation. The characteristic of donors is shown in Table 1.

Volume of collected BM and total number of nucleated cells were comparable as well-median: $1161 \mathrm{ml}$ in the group not referred for autotransfusion vs $1220 \mathrm{ml}$ in the control group; median $205 \times 10^{8}$ cells vs $202 \times 10^{8}$ cells, respectively. Total number of CD34-positive cells was also similar for both cohorts: $10.5 \times 10^{7}$ cells vs $12.9 \times 10^{7}$ cells (Table 1 ).

The analysis was approved by the local Bioethics Committee.

Preoperative autologous blood donation before BM harvest is routinely performed in many collection centers. However, many authors recommend to reduce the frequency of autologous blood transfusion in BM donors [7-11]. Some other centers collect autologous blood but infuse it only in case of significant drop of $\mathrm{Hb}$ level following BM harvest [2].

In this study, a total of 53 BM harvests were analyzed. The number of donors was limited because the analysis was performed at a single transplantation center. However, this approach allowed for homogeneity with regard to harvesting technique, which was performed uniformly according to local procedures by five experienced physicians specialized in hematology and transplantation medicine.

The donors harvested during the pandemic were older than control group, probably due to the fact, that donor selection priorities have been modified-logistical reasons like possible transport delay had to be taken into account.

Like other authors, we assessed the drop of hemoglobin after blood donation. The donors who donated autologous blood had lower hemoglobin pre-harvest compared to the control grouphowever, the difference was not statistically significant. 
Table 1. Characteristic of donors, laboratory analysis and bone marrow.

\begin{tabular}{|c|c|c|c|}
\hline & Patients with autotransfusion & Patients without autotransfusion & $\boldsymbol{p}$ \\
\hline Total number of donors & 33 & 20 & \\
\hline Gender of donors; male/female & $23 / 10$ & $13 / 7$ & 0.72 \\
\hline Age of donors [years]; (median, range) & $25(18-41)$ & $37(18-49)$ & $<0.001$ \\
\hline Female & $21(18-40)$ & $33(24-47)$ & 0.03 \\
\hline Male & $25(18-41)$ & $37(20-49)$ & 0.001 \\
\hline Weight of donors [kg]; (median, range) & $75(57-108)$ & $78(59-105)$ & 0.36 \\
\hline $\begin{array}{l}\text { Interval between workup and BM donation [days]; } \\
\text { (median, range) }\end{array}$ & $16(13-29)$ & $15(13-26)$ & 0.77 \\
\hline Female & $17(13-29)$ & $14(13-23)$ & 0.60 \\
\hline Male & $16(13-28)$ & $15(14-26)$ & 0.82 \\
\hline $\begin{array}{l}\mathrm{Hb} \text { concentration in blood in day of initial workup }[\mathrm{g} / \mathrm{dl}] \text {; } \\
\text { (median, range) }\end{array}$ & $15.3(12.5-17.0)$ & $15.1(12.8-17.5)$ & 0.78 \\
\hline $\begin{array}{l}\text { Hb concentration in blood-before harvest [g/dl]; } \\
\text { (median, range) }\end{array}$ & $14.0(10.6-17.3)$ & $14.9(12.5-16.6)$ & 0.34 \\
\hline Female & $11.5(10.6-14.1)$ & $13.2(12.5-15.9)$ & 0.014 \\
\hline Male & $14.6(13.3-17.3)$ & $15.2(13.7-16.6)$ & 0.10 \\
\hline $\begin{array}{l}\text { Hb concentration in blood } 1 \text { day after harvest }[\mathrm{g} / \mathrm{dl}] \text {; } \\
\text { (median, range) }\end{array}$ & $11.1(8.30-13.8)$ & $11.5(8.7-13.4)$ & 0.94 \\
\hline Female & $9.0(8.3-11.1)$ & $9.3(8.7-11.8)$ & 0.31 \\
\hline Male & $12.1(10.6-13.8)$ & $12.1(10.3-13.4)$ & 0.67 \\
\hline Total volume of marrow harvested [ml]; (median, range) & $1220(643-1423)$ & $1161(668-1572)$ & 0.27 \\
\hline Female & $1209(865-1340)$ & $1015(668-1315)$ & 0.11 \\
\hline Male & $1220(643-1423)$ & $1187(670-1572)$ & 0.79 \\
\hline Number of CD34-positive cells $\times 10^{7}$; (median, range) & $12.9(5.6-24.3)$ & $10.5(4.2-24.5)$ & 0.69 \\
\hline Female & $9.7(5.6-22.8)$ & $9.8(4.2-18.1)$ & 0.74 \\
\hline Male & $13.1(5.7-24.3)$ & $12.8(6.3-24.5)$ & 0.92 \\
\hline Nucleated BM cells $\times 10^{8} / \mathrm{kg}$ donor body mass; (median, range) & $2.53(1.38-3.86)$ & $2.77(1.27-4.33)$ & 0.14 \\
\hline Female & $2.36(1.96-3.86)$ & $2.99(1.98-4.33)$ & 0.36 \\
\hline Male & $2.61(1.38-2.93)$ & $2.69(1.27-4.08)$ & 0.27 \\
\hline
\end{tabular}

Additionally, we analyzed the hemoglobin level separately for men and women before donation (Table 1). For women, the group intended for autotransfusion had lover $\mathrm{Hb}$ level (median: $11.5 \mathrm{~g} / \mathrm{dl}$, range: $10.6-14.1)$ compared to the group not referred $(13.2 \mathrm{~g} / \mathrm{dl}$, range: $12.5-15.9), p=0.014$. The effect was not seen in men.

Some authors reported pre-harvest $\mathrm{Hb}$ drop in donors referred for autotransfusion as statistically significant for all donors, not only for women $[3,9]$. However, comparison of results obtained in other hospitals may be difficult due to different routines. The noticeable differences consist of number of red cell concentrate units collected and interval between blood donation and BM harvest (sometimes 3-7 days). Low volume of donated blood and about 2 weeks between donation and transfusion can make the hemoglobin drop in our center relatively low.
Next, we compared the level of $\mathrm{Hb}$ on the day following the harvest. For the second time, donors who had received autologous transfusion had similar values compared to donors who did not (the same effect was found in men and women). Our results confirm the conclusions of other authors about limited effects of autotransfusion for donor safety.

Even if autotransfusion does not affect hemoglobin level, the blood loss is a factor which induces hematopoiesis. For this reason, the BM collection could potentially be more effective. Verification of this hypothesis was the main objective of our research. According to our best knowledge, there is no literature data on this topic.

We assessed the efficiency of harvest by comparison of WBC and CD34-positive cells in BM collected from donors referred and 
not referred for autotransfusion. We observed no statistically significant differences for neither of these parameters.

Additionally, we analyzed the number of collected cells per $\mathrm{kg}$ of body weight. Usually the total nucleated cell dose was calculated per $\mathrm{kg}$ of recipient weight, but the same number of cells may be not be sufficient for every recipient. We found no differences between the donors with and without the autologous transfusion.

Our study has some important limitations related to its retrospective nature. In particular, it would be valuable to evaluate the effect of autotransfusion on the quality of the products using some more sensitive techniques like reticulocyte count, immature reticulocyte fractions, and stem cell subpopulations. Unfortunately, these parameters are not routinely tested in our center and therefore respective data were unavailable for the analysis.

In conclusion, we evaluated the effect of autologous blood donations based on two factors: level of hemoglobin in BM donors and the number of collected cells in obtained product. Our results do not support the routine use of autologous blood transfusion for BM donors. However, it cannot be excluded that in a certain group of donors autotransfusion should still be considered e.g. in case of significant weight disparity between donor and recipient, or low level of input hemoglobin. According to a new procedure introduced in our center, autotransfusions are not routinely used anymore. Feasibility and safety of this approach will be evaluated including attempt to select donors with an increased risk of postoperative anemia.

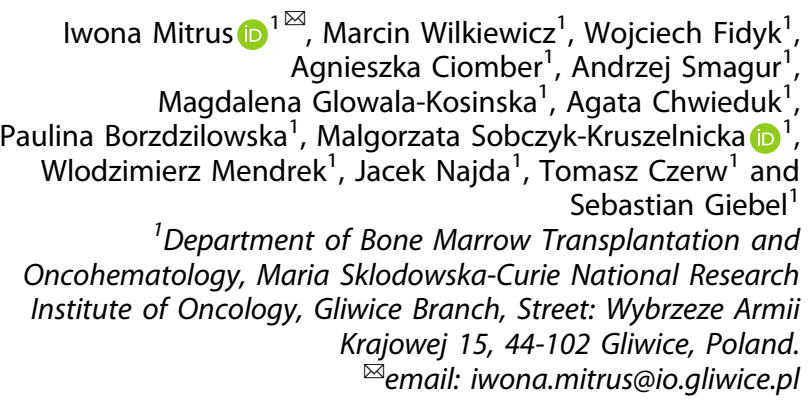

\section{REFERENCES}

1. Lown RN, Philippe J, Navarro W, van Walraven SM, Philips-Johnson L, Fechter M, et al. Unrelated adult stem cell donor medical suitability: recommendations from the World Marrow Donor Association Clinical Working Group Committee. Bone Marrow Transplant. 2014;49:880-6.

2. Spitzer TR, Sugrue MW, Gonzalez C, O'Donnell P, Confer D, Fuchs E, et al. Transfusion practices for bone marrow harvests: a survey analysis from the $A A B B$
Bone Marrow Quality Improvement Initiative Working Group. Bone Marrow Transplant. 2017:52:1199-1200.

3. Fujiwara Sl, Ikeda K, Kino S, Tanaka A, Hasegawa Y, Fujino K, et al. Clinical significance of autologous blood transfusions in bone marrow harvest from unrelated donors. Int J Hematol. 2020;111:833-9.

4. Farhadfar N, Murthy HS, Logan BR, Sees JA, Ayas M, Battiwalla M, et al. Impact of autologous blood transfusion after bone marrow harvest on unrelated donor's health and outcome: a CIBMTR analysis. Bone Marrow Transplant. 2020;55:2121-31.

5. Kim-Wanner SZ, Luxembourg B, Schmidt AH, Schäfer R, Möller N, Herbert E, et al. Introduction of principles of blood management to healthy donor bone marrow harvesting. Vox Sang. 2020;115:802-12.

6. Sutherland DR, Anderson L, Keeney M, Nayar R, Chin-Yee I. The ISHAGE guidelines for CD34+ cell determination by flow cytometry. International Society of Hematotherapy and Graft Engineering. J Hematother. 1996;5:213-26.

7. Mijovic A, Britten C, Regan F, Harrison J. Preoperative autologous blood donation for bone marrow harvests: are we wasting donors' time and blood? Transfus Med. 2006;16:57-62.

8. Manuel SP, Spitzer TR, Ishizawa Y. Preoperative autologous blood donation in healthy bone marrow donors contributes to pre-procedure anemia. Bone Marrow Transplant. 2017;52:1191-3.

9. Gilli IO, Vigorito AC, Benites BD. Revisiting old practices: more restricted indication of preoperative autologous blood donation in healthy bone marrow donors according to baseline hemoglobin levels. Transfus Apher Sci. 2019;58:323-5.

10. Arora K, Kelley J, Martinez F, Tholpady A. Preoperative autologous blood collection before bone marrow harvests in haploidentical related donors: is it justified? Transfusion. 2018;58:1618-25.

11. Lysák D, Hejretová $L$, Hrabetová $M$, Jindra P. Should we stop collecting the preoperative autologous blood before bone marrow harvest? J Clin Med. 2021;10:2134.

\section{AUTHOR CONTRIBUTIONS}

IM wrote the manuscript. MSK, WM, JN, TC, SG performed bone marrow collections and provided patient data. MW, WF, ACiomber, AS, MGK, AChwieduk, and PB performed laboratory analyses and collected the data. SG reviewed the manuscript. All authors read the manuscript and approved the final version.

\section{COMPETING INTERESTS}

The authors declare no competing interests.

\section{ADDITIONAL INFORMATION}

Correspondence and requests for materials should be addressed to Iwona Mitrus.

Reprints and permission information is available at http://www.nature.com/ reprints

Publisher's note Springer Nature remains neutral with regard to jurisdictional claims in published maps and institutional affiliations. 